This is an electronic reprint of the original article. This reprint may differ from the original in pagination and typographic detail.

\author{
Author(s): Irmola, Tero Matti; Häkkinen, Arja; Järvenpää, Salme; Marttinen, Ilkka; Vihtonen, \\ Kimmo; Neva, Marko
}

Title: $\quad$ Reoperation Rates Following Instrumented Lumbar Spine Fusion

Year: $\quad 2018$

Version:

Please cite the original version:

Irmola, T. M., Häkkinen, A., Järvenpää, S., Marttinen, I., Vihtonen, K., \& Neva, M. (2018). Reoperation Rates Following Instrumented Lumbar Spine Fusion. Spine, 43(4), 295-301. https://doi.org/10.1097/BRS.0000000000002291

All material supplied via JYX is protected by copyright and other intellectual property rights, and duplication or sale of all or part of any of the repository collections is not permitted, except that material may be duplicated by you for your research use or educational purposes in electronic or print form. You must obtain permission for any other use. Electronic or print copies may not be offered, whether for sale or otherwise to anyone who is not an authorised user. 
SPINE An International Journal for the study of the spine Publish Ahead of Print

DOI: $10.1097 / B R S .0000000000002291$

\section{REOPERATION RATES FOLLOWING INSTRUMENTED LUMBAR SPINE FUSION}

Irmola T., MD*, Häkkinen A., Prof**, Järvenpää S., MSc **, Marttinen I., MD*, Vihtonen K., MD, PhD* and Neva M.H.,MD,PhD *

*Department of Orthopaedics and Trauma, Tampere University Hospital, Finland

**Department of Physical Medicine and Rehabilitation, Jyväskylä Central Hospital, Finland **Department of Health Sciences, University of Jyväskylä, Finland

Corresponding author:

Tero Irmola, MD

PO Box Hukankatu 4 A, 33530 Tampere, Finland.

Tel: +358 407383394, Fax: +358331178091 E-mail: tero.irmola@fimnet.fi

The manuscript submitted does not contain information about medical device(s)/drug(s).

The Competitive State Financing of the Expert Responsibility Area of Tampere University Hospital funds were received in support of this work.

Relevant financial activities outside the submitted work: employment, payment for lecture. 


\section{Abstract}

Study design. Prospective cohort study

Objective. This study evaluated the cumulative reoperation rate and indications for reoperation following instrumented lumbar spine fusion (LSF).

Summary of Background Data. LSF reduces disability and improves health-related quality of life for patients with several spinal disorders. The rate of instrumented LSF has drastically increased over the last few decades. The increased incidence of LSF, however, has led to increased reoperation rates.

Methods. The data are based on the prospective LSF database of Tampere University Hospital that includes all elective indications for LSF surgery. A total of 433 consecutive patients (64\% women, mean age 62 years) who underwent LSF in Tampere University Hospital between 2008 and 2011 were evaluated and indications for reoperations were rechecked from patient records and radiographs. The most common diagnosis for the primary surgery was degenerative spondylolisthesis and the mean follow-up time was 3.9 years. The cumulative incidence of reoperations and the "time to event" survival rate was calculated by Kaplan-Meier analysis.

Results. By the end of 2013, 81 patients had undergone at least one reoperation. The cumulative reoperation rate at two years was $12.5 \%$ (95\% confidence interval $[95 \% \mathrm{Cl}]$ : 9.7-16.0) and at 4 years $19.3 \%(95 \% \mathrm{Cl}: 15.6-23.8)$. The most common pathology leading to reoperation was adjacent segment pathology with a cumulative reoperation rate of $8.7 \%$ (95\% Cl: $6.1-12.5)$ at 4 years. The corresponding rates for early and late instrumentation failure were $4.4 \%$ (95\% Cl: $2.7-7.0)$ and $2.9 \%(95 \% \mathrm{Cl}: 1.9-7.1)$, respectively, and for acute complications, $2.5 \%(95 \% \mathrm{Cl}: 1.4-4.5)$.

Conclusions. Although previous studies reported that early results of spinal fusion are promising, one in five patients required reoperation within 4 years after surgery. Patients and surgeons should be aware of the reoperation rates when planning fusion surgery.

Key words: complications, instrumented lumbar spine fusion, reoperation, adjacent segment pathology

\section{Level of Evidence: 4}




\section{Introduction}

Lumbar spine fusions (LSF) are performed to treat several spinal disorders when conservative treatment fails. LSF is effective for treating degenerative and isthmic spondylolisthesis [1,2]. Prospective randomized studies revealed that posterolateral fusion is more efficient than an exercise program for short term improvent of function and pain relief in adult isthmic spondylolisthesis $[3,4]$. Weinstein et al. [2] reported that decompressive laminectomy (with or without fusion) has advantages over nonoperative treatment for treating degenerative spondylolisthesis. A Cochrane review, however, revealed no clear benefits of surgery over nonoperative treatment for lumbar spinal stenosis [5]. In a recent randomized controlled trial of 247 patients with lumbar spinal stenosis with or without degenerative spondylolisthesis, Försth et al. [6] reported no benefit of adding fusion to decompression surgery, thus, fusion in spinal stenosis surgery is controversial. In contrast a randomized controlled trial by Ghogawala et al. [7] revealed that the addition of fusion to laminectomy slightly improved outcomes in 66 patients with degenerative grade I spondylolisthesis. The value of spinal fusion for the treatment of chronic low back pain is controversial [8-10]. Spinal fusions are also performed in revision spine surgery and for the treatment of scoliosis and recurrent disc herniations [11].

The incidence of spinal fusion surgery has drastically increased over the past few decades $[11,12]$, and thus the incidence of reoperations has also increased. Any indication resulting in a return to the operating room is considered a reoperation, which is an undesirable outcome of LSF that causes pain and inconvenience for the patient and as well as additional expense to the patient, society, and employer. Based on the timing, reoperations are classified as early or late. Early reoperations are caused by an acute complication $(<3$ months after surgery), and instrumentation failure or early nonunion $(<1$ year). Indications for reoperation 1 year or more after fusion may be pseudoarthrosis, persistent pain or recurrence of symptoms or adjacent segment pathology (ASP) [13,14]. According to population-based analysis, cumulative reoperation rates accounting for any unplanned return to the operating room following lumbar spine surgery, including both decompression or fusion surgery are $12.5 \%-14.0 \%$ at 4 years $[13,15]$. The Finnish National Hospital Discharge Register indicates $\sim 20 \%$ cumulative risk for reoperation within 15 years after spinal fusion [13]. The length of the fusion influences to the reoperation rate. Howe et al. [16] reported a 
reoperation rate as high as $35 \%$ during a mean 26 -month follow-up of instrumented fusions from the thoracic spine to the pelvis.

The aim of the present study was to determine the overall rate, indications and timing of reoperations- following instrumented LSF- in a prospectively collected cohort in a single university hospital experience.

\section{Materials and Methods}

Since the beginning of 2008, all adult patients from the Pirkanmaa district undergoing elective LSF at Tampere University Hospital were invited to join a prospective follow-up study. The data were collected as part of standard clinical practice and operation details were recorded in a database. Formal approval to collect the data was granted by the Ethics Committee of Tampere University Hospital and all patients provided signed written consent prior to data collection. As Finland has a national health insurance system, all hospitals cover a certain area and population and reoperations are performed in same hospital as the initial operation. Between 2008 and 2011, 433 adult patients in the Pirkanmaa district underwent elective LSF and formed the study group. Of the 433 patients, 19 died before the end of 2013. The information about reoperations performed by the end of 2013 was collected from the database, and indications for reoperations were confirmed from patient records, radiographs and magnetic resonance images. The time between the index operation and reoperation was recorded. The disability was assessed by using the Finnish validated Oswestry Disability Index (ODI) version 2.0 (17). The questionnaire data was collected preoperatively and at two years from index operation.

Reoperations were classified into seven categories.

1. Acute complications were identified within a few months of the index operation and included hematoma, wound or deep infection, spinal fluid leak, new neurologic deficit, or mislocated instrumentation. 2. Residual stenosis occurred when symptoms remained and appeared from undecompressed levels within fused segments or adjacent levels. 3. Persistent pain after the index operation indicated unexpectedly small benefits associated with spinal 
fusion. 4. Early failure was considered instrumentation failure or early nonunion detected during the first postoperative year. 5. Late failures occurred one year or more after the index fusion and comprised pseudoarthrosis, which was detected by loss of fixation, i.e., halo around the fixation point, pullout of pedicle screws, broken implant, or motion during surgical exploration, or progression of deformity. ASP was noted as development of pathology at the mobile adjacent segment next to the fused area, comprising disc degeneration, disc space narrowing, disc herniation, spinal stenosis caused by hypertrophic facet arthritis and/or osteophyte formation, spondylolisthesis, instability, scoliosis, or vertebral compression fracture as defined earlier in the classification system of Park et al. $[18,19]$. 7. Implant removal was also classified as reoperation.

\section{Statistical Analysis}

The data are presented as counts with percentages or as means with range or standard deviation (SD). We calculated the $95 \%$ confidence interval $(\mathrm{Cl})$ for the major outcomes. We performed a time-to-event analysis using the product-limit estimate of the Kaplan-Meier cumulative survival function to estimate the cumulative reoperation rate. The $\alpha$-level was set at 0.05. SPSS Statistics for Windows version 19.0 (IBM Corp., Armonk, NY) was used for the analysis.

\section{Results}

Of the 433 LSF patients, 81 underwent at least one reoperation by the end of 2013 with a mean (SD) follow-up time of 3.9 (1.2) years. There were 32 patients who required reoperation within one year of the index operation. The cumulative reoperation rate at 2 years (95\%) was $12.5 \%$ (Cl: $9.7-16.0)$ and at 4 years, $19.3 \%$ (Cl: 15.6-23.8; Figure 1). The most common indications for primary surgery were degenerative spondylolisthesis and spinal stenosis accounting for $65 \%$ of the patients (Table 1). The primary fusion was longer than two levels in $35 \%$ of patients $(158 / 433)$ and $37 \%$ in patients who underwent reoperation (30/81). In the patients, who were not reoperated the preoperative mean (SD) ODI was 46 (16) and at two years post fusion 21 (19). Correspondingly, among patients who required 
reoperation within one year, the preoperative ODI values were 47 (17) and at two years after index operation 20 (16).

Acute complications $(\mathrm{n}=11)$ were noted within 32 days of the index operation and reoperation was performed mean of 14 days after the index operation. Four patients required reoperation due to postoperative hematoma, two due to cerebrospinal fluid leakage, and three due to deep surgical site infections. One patient required reoperation due to neurologic deficit and pedicle screw misplacement, and one due to total L5 paresis, which appeared 2 weeks after LIII-LV fusion. Wound hematomas were evacuated and dural lesions were repaired by suturing. All wound infections underwent debridement without implant removal. Improper screw placement was detected in the postoperative radiographs and computed tomography images. Irritation pain of the lower extremity was relieved after correcting screw position. In one patient with neurologic deficit appearing 2 weeks after surgery magnetic resonance imaging showed spinal stenosis at the LIV/LV level indicating early adjacent segment pathology. In the reoperation, spinal stenosis was decompressed and fusion was extended to the sacrum. The total L5 nerve root paresis did not recover during the follow-up.

Early failure was detected in 17 cases. Early failures were reoperated a mean of 10 months after the index operation. In two cases, however, patient-related factors postponed the reoperations to 1.5 and 3.6 years after the index operation. Early instrumentation failures included five screws penetrating the anterior part of the vertebral body, two endplate violations or fractures, four broken screws, five loosened screws, and one pullout of the pedicle screws. Early nonunions were noted in three cases.

ASP was noted in 34 cases and the reoperation was performed a mean of 2.3 years after the index fusion. Symptomatic degeneration proximal to the fused segments dominated in our study, and degeneration of spinal levels distal to the fused segments was noted in only six cases, disc herniation in two cases, instability and spondylolisthesis in two cases, and facet hypertrophy and lateral stenosis in two cases. Pathology proximal to the fused segment overlapped and comprised proximal junction stenosis in 18 cases, proximal junction instability in 9 cases, and proximal kyphosis or fracture in 5 cases. Disc herniations, synovial cysts, and facet hypertrophies were also observed. 
Late failures were detected in 10 of the reoperated cases. Pseudoarthrosis was detected in all cases by fragmentation in the fusion area, loosened screws, or rod breakages. Late failures were reoperated a mean of 2.4 years after the index operation (Table 2).

Indications for reoperation are time-dependent and the most common indication depends on which time interval from the index surgery is evaluated. Within 1 and 2 years after the index operation, the most common reason for reoperation was early failure with cumulative reoperation rates of $3.4 \%(\mathrm{Cl}: 2.0-5.6)$ and $3.9 \%(\mathrm{Cl}: 2.4-6.2)$, respectively (Table 3). Cumulative reoperation rates for late failures were $1.3 \%(\mathrm{Cl}: 0.5-3.6)$ at 2 years and $2.9 \%(\mathrm{Cl}: 1.9-7.1)$ at 4 years. When evaluating the 4 -year period after the initial operation, ASP was the main cause of the first reoperation with an incidence of $8.7 \%(\mathrm{Cl}$ : 6.1-12.5; Figure 2A-C).

\section{Discussion}

The present prospective study revealed cumulative reoperation rate for LSF of $12.5 \%$ at 2 years and $19.3 \%$ at 4 years. The most common indication for reoperation was ASP accounting for $8.7 \%$ of the reoperations.

In a retrospective cohort analysis of Medicare claims for 16,955 fusion procedures, Deyo et al. [19] reported a reoperation rate of $9.8 \%$ at 2 years after surgery. Another retrospective cohort study [20] focusing on the impact of obesity reported that $20.5 \%$ (150/732 patients) of patients that had undergone instrumented LSF (median follow-up: 25 months) for degenerative spine disease required revision. Those results are comparable with our $12.5 \%$ reoperation rate at 2 years when taking into account that all spinal disorders, including degenerative diseases, scoliosis, and spondylolysis as well as reoperations of previously fused patients, were included in the present study. The reoperation rate at two years is fairly high, but does not automatically reflect a poor outcome from the initial surgery $[13,21]$. At 2 years, the spinal fusions appeared to be successful in terms of decreasing disability and improving health-related quality of life, as previously reported by Pekkanen et al. using this same database [22]. The most common indications for reoperation within 2-year 
follow-up in the present series were acute complications and early implant failures, and the final result is probably good if corrected early. Disability captured by ODI showed tendency to improve at two years after index operation, even though patients were reoperated within one year.

Martin et al. [13] studied two cohorts (from 1990 to 1993 and from 1997 to 2000) of patients that underwent lumbar decompression or lumbar fusion surgery for degenerative spine disorders. The cohorts comprised $9.4 \%$ and $19.1 \%$ fusion procedures and the 4-year reoperation rates were $12.4 \%$ and $14.0 \%$, respectively. Lad et al. [23] reported reoperation rates of patients who underwent decompression alone (15.2\%) or decompression with fusion (13.3\%) with a 5-year follow-up. They also reported the revision surgery in patients with instrumented fusions was slightly higher (14.5\%) than that for patients with noninstrumented fusions $(10.5 \%)$ [23]. The higher reoperation rate $(19.3 \%)$ for instrumented LSF in our follow-up may suggest that the reoperation risk is increased in instrumented fusions compared to non-instrumented fusions or decompressions alone. When taking into account the results of the recent study by Försth et al. [6], in which the outcome of decompression was similar to that of fusions for treating spinal stenosis and degenerative spondylolisthesis, the rationale leading to the large increase in the incidence of instrumented fusions during last few decades may be debatable [6]. It should be noted, however, that many patients were excluded in Martin et al. [13] (1793/26,675 patients) and in Lad et al. [23] (680/26,620 patients) because the patients had undergone lumbar spine surgery within the preceding 2 or 3 years, or the procedure codes indicated repeated surgery. In contrast, in our study, even $25 \%$ of the primary surgeries were actually reoperations of the spine, and repeat surgeries are associated with greater rates of complications [24].

Acute complications were detected within a few months postoperatively in our study. Liu et al. [25] reported the rates, reasons, and risk factors for unplanned lumbar spinal surgery reoperation during the primary admission. In their study, 3936 patients underwent lumbar spinal surgery, $60 \%$ (2359) with posterior or transforaminal interbody fusion. The unplanned reoperation rate was $2.08 \%$ during the primary admission, and the most common causes of reoperation were wound infection and screw misplacement. Patients who were readmitted for revision, however, were not included in the study. Liu et al. [25] pointed out that the unplanned reoperation rate may be a useful indicator of quality. In our study, the 
cumulative reoperation rate of $2.5 \%$ at 1 year (including readmitted patients) was comparable to the rates reported by Liu et al. [25]. In addition, the reasons resulting in the reoperation were similar. The rate of surgical site infection after posterior fusion and instrumentation is reported to be between $<1 \%$ and $5 \%$ [26]. In another registry-based on study with a 26-month follow-up of 481 patients that underwent instrumented posterior LSF for degenerative spine, deformity, fractures, or tumors, 43 (8.9\%) developed an acute deep surgical infection [27]. Although this reoperation rate seems quite high, it is not directly comparable with our results because that study included tumors and fractures, which were excluded from our study.

Early failures were the most common reason for reoperation at 1 and 2 years $(3.4 \%$ and $3.9 \%$, respectively). Reoperations were categorized as early failure when instrumentation failed, screws broke, or early nonunion was diagnosed within 1 year after the index operation. In two cases, when a failure was detected, patient-related factors shifted their reoperations to 1.5 and 3 years after index operation, which may have influenced the Kaplan-Meier survival curve. The very active post-operative rehabilitation program in our hospital may also have influenced the number of early failures in the study [28]. Late failures were seen in 10 cases. A minimum of 2 years of follow-up, however, is too short when evaluating the number of reoperations in this category. A longer follow-up is necessary for assessing late failures.

ASP is a definition used for changes that occur at adjacent segments [29]. Lee et al. [30] defined ASP as the need for reoperation at an adjacent segment. A validated outcome measurement to diagnose, quantify, or classify ASP has not yet been invented, and therefore, in the present study, we used the classification of Park et al. [18], which is commonly used in the literature $[29,31]$. The most common reason for reoperation in our study was ASP, leading to $8.7 \%$ of the reoperations. The mean annual incidence of ASP after LSF was previously reported to be $3.9 \%$ [31], which is comparable to our reoperation rate due to ASP. Laminectomy adjacent to the fusion and sagittal imbalance consistently associates with ASP [32]. Furthermore, Alentado et al. [31] concluded that antidepressant use, diagnosis of degenerative scoliosis, fusion from L4 to S1, and low sacral slope predict the development of ASP. In our study, none of the patients had a laminectomy performed adjacent to the fusion. We did not have full spine radiographs, and therefore the sagittal balance and sacral slope could not be measured. 
One limitation of our study is that we did not evaluate patient comorbidities, which might impact the primary outcome. Categorizing reoperations as a primary outcome also has several disadvantages. Reoperation is a surgeon-dependent outcome, and there are no clear and objective indications for reoperations. Definitions of failures are not uniform and the surgeon's decision regarding which symptoms require reoperation is subjective and may vary. Another limitation of this study is that the index operation was a reoperation in $25 \%$ of the cases, and repeat surgery is associated with greater complications and lower effectiveness compared with the initial surgery $[24,33]$. Finally, the mean follow-up time of 3.9 years was rather short when evaluating the reoperation rate for LSF. Therefore, our study may only show the beginning of the reoperations, as other studies have demonstrated that the cumulative probability of reoperation increases linearly [15, 34]. One confounding factor is patients who died before the end of 2013 and thus the follow-up time remained shorter, but is natural when studying an older patient population. A study from South Korea excluded patients who died from the analysis [15].

A strength of this study is the population-based, nonselected, patient cohort, including almost every patient who underwent elective instrumented LSF between 2008 and 2011 among patients in the Pirkanmaa region. Population-based studies are less susceptible to selection or nonresponse biases than typical case series studies [13]. Another strength is the small number of drop-outs, small amount of missing data, and adherence to the study protocol. Almost all patients (98\%) enrolled in our study completed the follow-up period, and the only missing follow-up data were due to patient death.

In our study, cumulative reoperation rates after instrumented LSF was $12.5 \%$ at 2 years and $19.3 \%$ at 4 years, which should be taken into account when planning fusion surgery. Although the rate is high, it comprehensively includes indications for primary fusion and reoperations. Reoperations are frequent after LSF, occurring in one in five subjects within 4 years. Therefore, the indication for instrumented LSF must be well defined and the risk for reoperation must be kept in mind and should be part of the preoperative consent discussion with the patient. 


\section{References}

1. Fischgrund JS, Mackay M, Herkowitz HN, et al. 1997 Volvo Award winner in clinical studies. Degenerative lumbar spondylolisthesis with spinal stenosis: a prospective, randomized study comparing decompressive laminectomy and arthrodesis with and without spinal instrumentation. Spine 1997;22:2807-12.

2. Weinstein JN, Tosteson TD, Lurie JD, et al. Surgical versus nonoperative treatment for lumbar spinal stenosis four-year results of the Spine Patient Outcomes Research Trial. Spine 2010;35:1329-38. doi:10.1097/BRS.0b013e3181e0f04d.

3. Möller H, Hedlund R. Surgery versus conservative management in adult isthmic spondylolisthesis--a prospective randomized study: part 1. Spine 2000;25:1711-5.

4. Ekman P, Möller H, Hedlund R. The long-term effect of posterolateral fusion in adult isthmic spondylolisthesis: a randomized controlled study. Spine J 2005;5:36-44. doi:10.1016/j.spinee.2004.05.249.

5. Zaina F, Tomkins-Lane C, Carragee E, et al. Surgical versus non-surgical treatment for lumbar spinal stenosis. Cochrane Database Syst Rev 2016:CD010264. doi:10.1002/14651858.CD010264.pub2.

6. Försth P, Ólafsson G, Carlsson T, et al. A Randomized, Controlled Trial of Fusion Surgery for Lumbar Spinal Stenosis. N Engl J Med 2016;374:1413-23. doi:10.1056/NEJMoa1513721.

7. Ghogawala Z, Dziura J, Butler WE, et al. Laminectomy plus Fusion versus Laminectomy Alone for Lumbar Spondylolisthesis. N Engl J Med 2016;374:1424-34. doi:10.1056/NEJMoa1508788.

8. $\quad$ Fritzell P, Hägg O, Wessberg P, et al.; Group Swedish Lumbar Spine Study. 2001 Volvo Award Winner in Clinical Studies: Lumbar fusion versus nonsurgical treatment 
for chronic low back pain: a multicenter randomized controlled trial from the Swedish Lumbar Spine Study Group. Spine 2001;26:2521-32.

9. Fairbank J, Frost H, Wilson-MacDonald J, et al. Randomised controlled trial to compare surgical stabilisation of the lumbar spine with an intensive rehabilitation programme for patients with chronic low back pain: the MRC spine stabilisation trial. BMJ 2005;330:1233. doi:10.1136/bmj.38441.620417.8F.

10. Brox JI, Sorensen R, Friis A, et al. Randomized clinical trial of lumbar instrumented fusion and cognitive intervention and exercises in patients with chronic low back pain and disc degeneration. Spine 2003;28:1913-21. doi:10.1097/01.BRS.0000083234.62751.7A.

11. Pannell WC, Savin DD, Scott TP, et al. Trends in the surgical treatment of lumbar spine disease in the United States. Spine $J$ 2015;15:1719-27. doi:10.1016/j.spinee.2013.10.014.

12. Deyo RA, Nachemson A, Mirza SK. Spinal-fusion surgery — the case for restraint. $N$ Engl J Med 2004;350:722-6. doi:10.1056/NEJMsb031771.

13. Martin BI, Mirza SK, Comstock BA, et al. Reoperation rates following lumbar spine surgery and the influence of spinal fusion procedures. Spine 2007;32:382-7. doi:10.1097/01.brs.0000254104.55716.46.

14. Cho K-J, Suk S-I, Park S-R, et al. Complications in posterior fusion and instrumentation for degenerative lumbar scoliosis. Spine 2007;32:2232-7. doi:10.1097/BRS.0b013e31814b2d3c.

15. Kim CH, Chung CK, Park CS, et al. Reoperation rate after surgery for lumbar spinal stenosis without spondylolisthesis: a nationwide cohort study. Spine J 2013;13:12307. doi:10.1016/j.spinee.2013.06.069. 
16. Howe CR, Agel J, Lee MJ, et al. The morbidity and mortality of fusions from the thoracic spine to the pelvis in the adult population. Spine 2011;36:1397-401. doi:10.1097/BRS.0b013e3181f453e2.

17. Pekkanen L, Kautiainen H, Ylinen J, et al. Reliability and validity study of the Finnins version 2.0 of the Oswestry Disability Index. Spine 2011;36:332-338. doi:10.1097/BRS.0b013e3181cdd702

18. Park P, Garton HJ, Gala VC, et al. Adjacent segment disease after lumbar or lumbosacral fusion: review of the literature. Spine 2004;29:1938-44.

19. Deyo RA, Martin BI, Ching A, et al. Interspinous spacers compared with decompression or fusion for lumbar stenosis: complications and repeat operations in the Medicare population. Spine 2013;38:865-72. doi:10.1097/BRS.0b013e31828631b8.

20. la Garza-Ramos De R, Bydon M, Abt NB, Sciubba DM, Wolinsky J-P, Bydon A, et al. The impact of obesity on short- and long-term outcomes after lumbar fusion. Spine 2015;40:56-61. doi:10.1097/BRS.0000000000000655.

21. Martin BI, Mirza SK, Comstock BA, et al. Are lumbar spine reoperation rates falling with greater use of fusion surgery and new surgical technology? Spine 2007;32:211926. doi:10.1097/BRS.0b013e318145a56a.

22. Pekkanen L, Neva M, Kautiainen H, et al. Decreased disability is associated with improved perceived quality of life following spinal fusion. Disabil Rehabil 2013;35:1364-70. doi:10.3109/09638288.2012.735339.

23. Lad SP, Babu R, Ugiliweneza B, et al. Surgery for spinal stenosis: long-term reoperation rates, health care cost, and impact of instrumentation. Spine 2014;39:97887. doi:10.1097/BRS.0000000000000314. 
24. Deyo RA, Martin BI, Kreuter W, et al. Revision surgery following operations for lumbar stenosis. $J$ Bone Joint Surg (Am) 2011;93:1979-86. doi:10.2106/JBJS.J.01292.

25. Liu J-M, Deng H-L, Peng A-F, et al. Unplanned Reoperation of Lumbar Spinal Surgery During the Primary Admission. Spine 2016;41:1279-83. doi:10.1097/BRS.0000000000001529.

26. Schuster JM, Rechtine G, Norvell DC, et al. The influence of perioperative risk factors and therapeutic interventions on infection rates after spine surgery: a systematic review. Spine 2010;35:S125-37. doi:10.1097/BRS.0b013e3181d8342c.

27. Núñez-Pereira S, Pellisé F, Rodríguez-Pardo D, et al. Implant survival after deep infection of an instrumented spinal fusion. Bone Joint $J$ 2013;95-B:1121-6. doi:10.1302/0301-620X.95B8.30784.

28. Tarnanen S, Neva MH, Dekker J, et al. Randomized controlled trial of postoperativeexercise rehabilitation program after lumbarspine fusion: study protocol. BMC Musculoskelet Disord 2012;13:123. doi:10.1186/1471-2474-13-123.

29. Kraemer P, Fehlings MG, Hashimoto R, et al. A systematic review of definitions and classification systems of adjacent segment pathology. Spine 2012;37:S31-9. doi:10.1097/BRS.0b013e31826d7dd6.

30. Lee JC, Lee S-H, Peters $\mathrm{C}$, et al. Adjacent segment pathology requiring reoperation after anterior cervical arthrodesis. Spine 2015;40:E571-7. doi:10.1097/BRS.0000000000000846.

31. Alentado VJ, Lubelski D, Healy AT, et al. Predisposing Characteristics of Adjacent Segment Disease After Lumbar Fusion. Spine 2016;41:1167-72. doi:10.1097/BRS.0000000000001493. 
32. Radcliff KE, Kepler CK, Jakoi A, et al. Adjacent segment disease in the lumbar spine following different treatment interventions. Spine $J$ 2013;13:1339-49. doi:10.1016/j.spinee.2013.03.020.

33. Deyo RA. Trends, major medical complications, and charges associated with surgery for lumbar spinal stenosis in older adults. JAMA 2010;303:1259-65. doi:10.1001/jama.2010.338.

34. Deyo RA, Mirza SK, Martin BI. Error in trends, major medical complications, and charges associated with surgery for lumbar spinal stenosis in older adults. JAMA 2011;306:1088-8. doi:10.1001/jama.2011.1300. 


\section{Figure Legends}

Figure 1.

Cumulative incidence of reoperation following lumbar fusion surgery

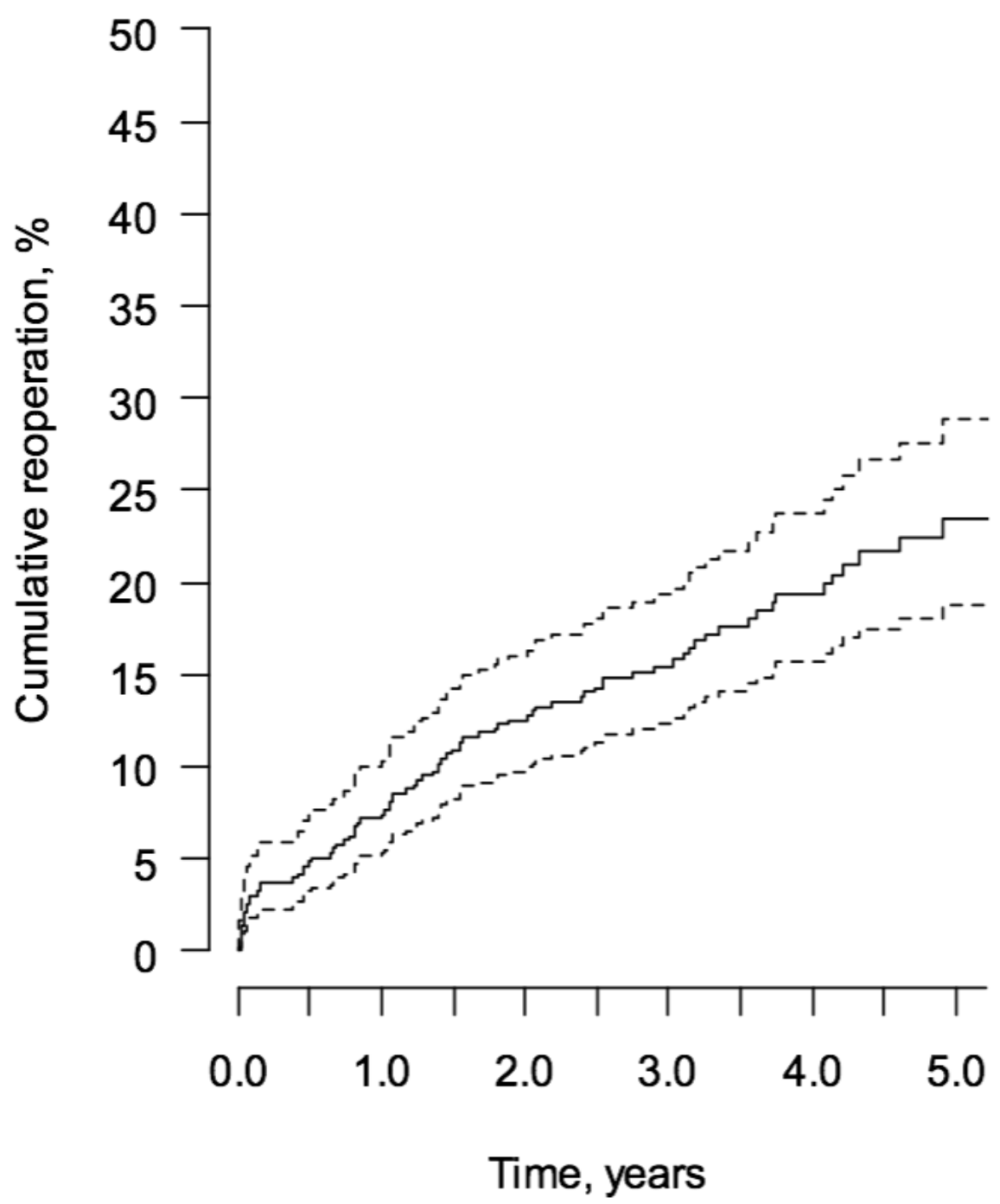

Figure 1. 
Figure 2.

Cumulative reoperation rates according to indication (A. Early failure, B. Adjacent segment pathology, C. Late failure). A. In two cases of early failure, patient-related factors postponed reoperations to 1.5 and 3.6 years after the index operation.

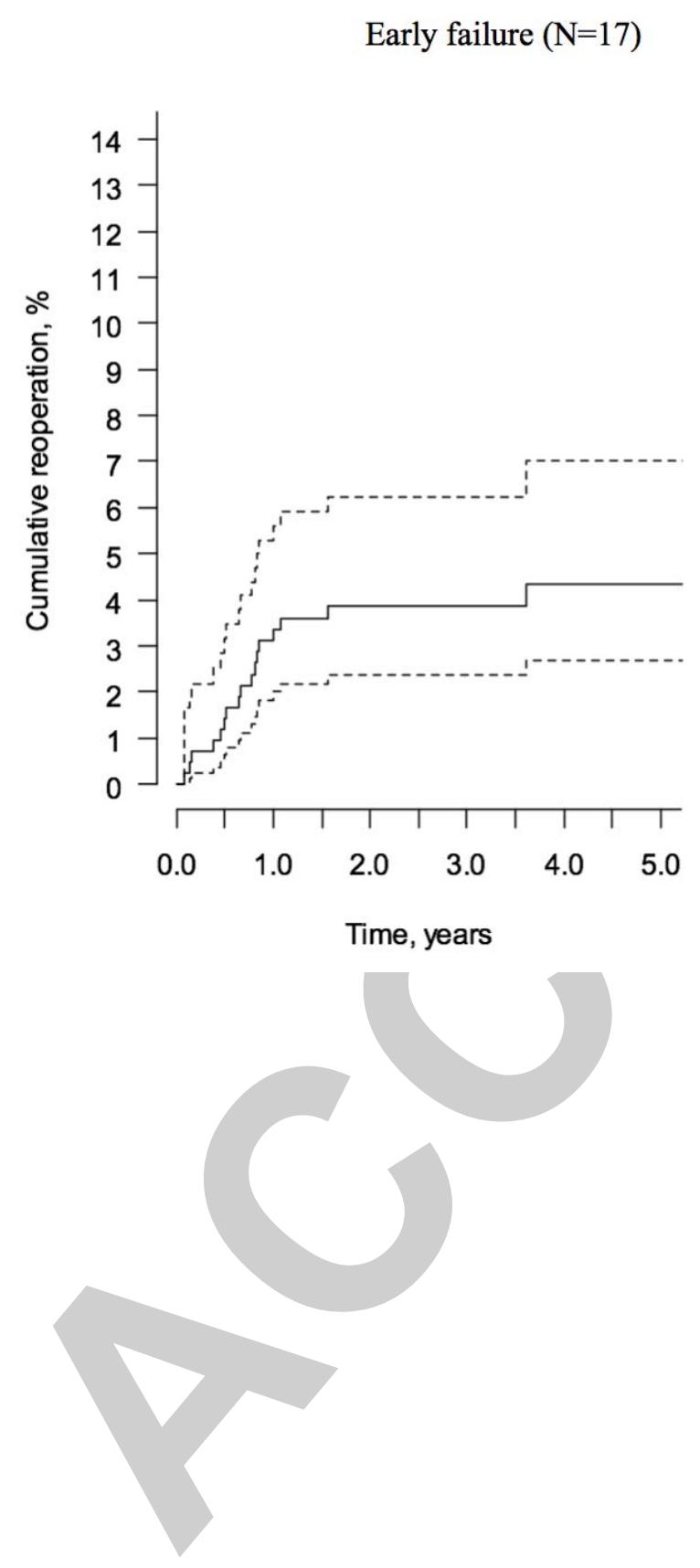

Copyright @ 2017 Wolters Kluwer Health, Inc. Unauthorized reproduction of this article is prohibited. 
$\operatorname{ASP}(\mathrm{N}=34)$

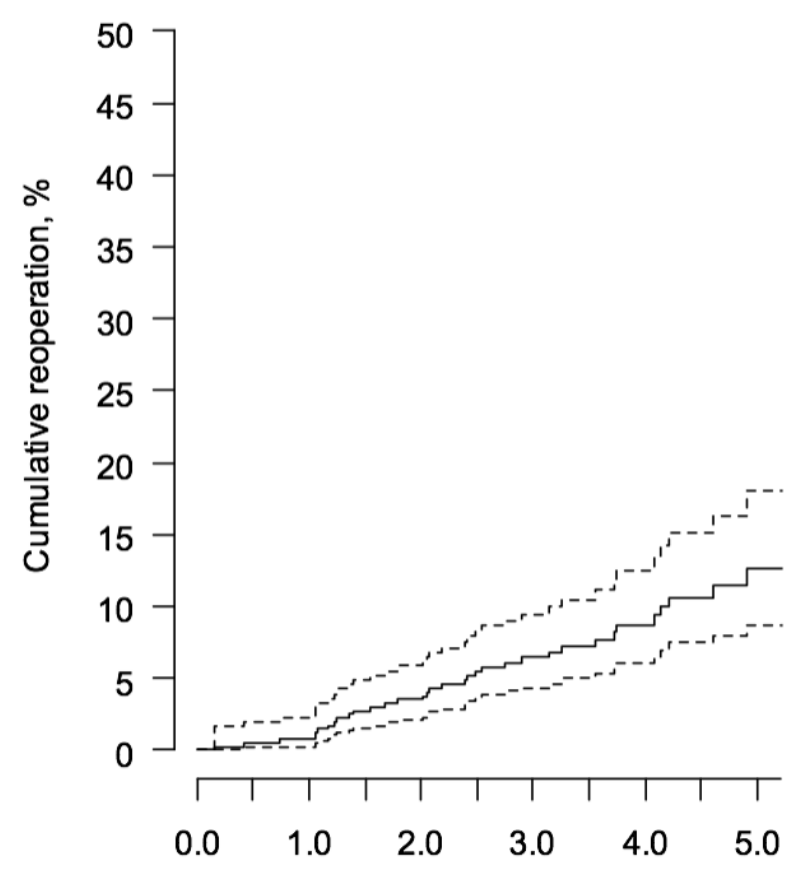

Time, years

Late failure $(\mathrm{N}=10)$

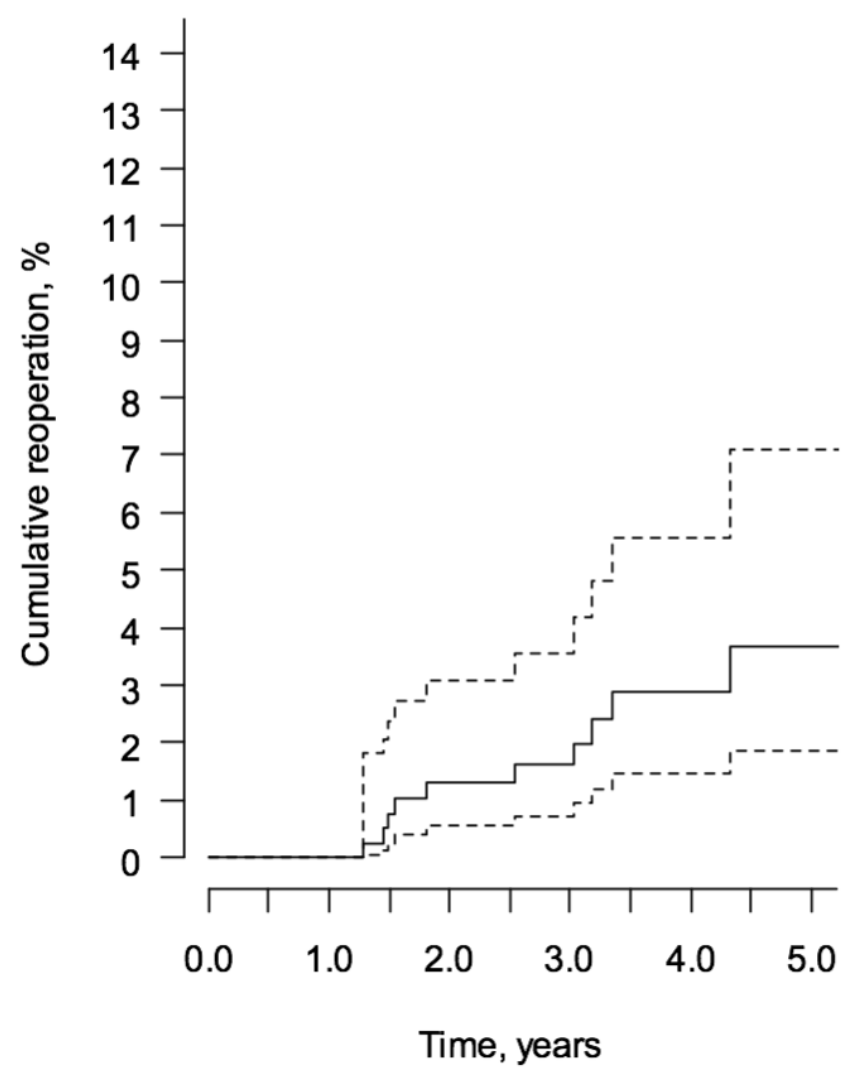

Copyright @ 2017 Wolters Kluwer Health, Inc. Unauthorized reproduction of this article is prohibited. 
Tables

Table 1. Baseline sosiodemographic and clinical data

\begin{tabular}{|l|c|c|}
\hline & $\begin{array}{c}\text { All } \\
\mathrm{N}=433\end{array}$ & $\begin{array}{c}\text { Re-operated } \\
\mathrm{N}=81\end{array}$ \\
\hline Women, n (\%) & $278(64)$ & $49(61)$ \\
\hline Age, years, mean (range) & $62(24-87)$ & $61(25-87)$ \\
\hline Body mass index, mean (SD) & $28.2(4.3)$ & $28.3(4.1)$ \\
\hline Back pain, VAS*, mean (SD) & $65(25)$ & $74(21)$ \\
\hline Leg pain, VAS*, mean (SD) & $66(25)$ & $71(24)$ \\
\hline Indication for the surgery, n(\%) & & $30(37)$ \\
\hline Degenerative spondylolisthesis & $189(44)$ & $20(24)$ \\
\hline Spinal stenosis & $93(21)$ & $10(12)$ \\
\hline Spondylolysis & $70(16)$ & $11(14)$ \\
\hline Degenerative disc disease & $43(10)$ & $3(4)$ \\
\hline Degenerative scoliosis & $18(4)$ & $3(4)$ \\
\hline Sequelae fracture & $13(3)$ & $4(5)$ \\
\hline Scoliosis (idiopathic, neuromuscular) & $5(1)$ & 0 \\
\hline Nonspecified & $2(1)$ & $22(27)$ \\
\hline Previously operated, $\mathrm{n}(\%)$ & $109(25)$ & \\
\hline
\end{tabular}

*VAS, visual analog scale 
Table 2. Mean time from the index operation according the indication for reoperation

\begin{tabular}{|l|c|c|c|}
\hline \multirow{2}{*}{ Indication for reoperation } & Number of cases & \multicolumn{2}{|c|}{ Time since index operation } \\
\hline & & Mean (SD) & Range \\
\hline Acute complication & 11 & $14(7)$ days & $1-32$ days \\
\hline Early failure & 17 & $10(10)$ months & $1-43$ months \\
\hline $\begin{array}{l}\text { Adjacent segment } \\
\text { pathology }\end{array}$ & 34 & $2.3(1.3)$ years & $0.2-4.9$ years \\
\hline Late failure & 10 & $2.4(1.0)$ years & $1.3-4.3$ years \\
\hline Residual stenosis & 3 & $4.7(4.0)$ months & $0.4-8.2$ months \\
\hline Persistent pain & 4 & $1.6(1.0)$ years & $0.8-3.1$ years \\
\hline Implant removal & 2 & $1.7(0.3)$ years & $1.4-1.9$ years \\
\hline
\end{tabular}




\section{Table 3.}

\begin{tabular}{|l|c|c|c|}
\hline \multirow{2}{*}{ Indication for reoperation } & \multicolumn{3}{|c|}{ Cumulative reoperation rate } \\
\hline & 1 year & 2 years & 4 years \\
\hline Acute complication & $2.5 \%(1.4$ to 4.5$)$ & $2.5 \%(1.4$ to 4.5$)$ & $2.5 \%(1.4$ to 4.5$)$ \\
\hline Early failure & $3.4 \%(2.0$ to 5.6$)$ & $3.9 \%(2.4$ to 6.2$)$ & $4.4 \%(2.7$ to 7.0$)$ \\
\hline Adjacent segment pathology & $0.7 \%(0.2$ to 2.2$)$ & $3.5 \%(2.1$ to 5.8$)$ & $8.7 \%(6.1$ to 12.5$)$ \\
\hline Late failure & 0 & $1.3 \%(0.5$ to 3.6$)$ & $2.9 \%(1.9$ to 7.1$)$ \\
\hline
\end{tabular}

